\author{
Manase Kudzai Chiweshe* \\ University of Zimbabwe, Harare, Zimbabwe \\ https://orcid.org/0000-0002-9781-6633

\section{Money, football and politics: Asiagate and the scourge of match-fixing in Zimbabwe}

\title{
Introduction
}

Whilst match-fixing in Zimbabwe has a long history, the darkest moments for the game came between 2007 and 2010 during what is now infamously known as Asiagate. The corruption scandal that rocked Zimbabwean football was spearhead by Wilson Raj Perumal who claimed that he had worked since 1997 with Zimbabwean football official to fix matches (Asiagate: ZIFA vindicated, 2014). Sport, especially football, can be a microcosm of wider social issues. In this paper, I explore how corruption in football (as encapsulated in the now infamous Asiagate scandal) is in many ways a reflection of a wider problem of corruption in the socio-political and economic context of Zimbabwe. Any scholarly endeavor into analyzing Asiagate corruption scandal in Zimbabwe needs to be placed within the context of corruption that has shaped Zimbabwe's political economy post-2000. Asiagate in many ways mirrors the multiple challenges facing accountability within public institutions in Zimbabwe. The scandal has far-reaching and lost lasting impacts on the national development of football in Zimbabwe. Analyzing the narratives emerging out of the Asiagate reports, DW.com sports concludes that:

It could be a Hollywood script. From kidnappings to death threats; from dressing-room violence to underworld Asian syndicates. The CEO of a national organisation arrested by anti-corruption police and almost 100 players, officials and administrators suspended. However, this is not a big-screen work of fiction. Rather this is the match-fixing scandal that has engulfed football in Zimbabwe (Asiagates scandal rocks Zimbabwe, 2012).

Corruption and football have overtime become synonymous within the Zimbabwean context. Governance of football in post-colonial times provides insights into how the game developed into a citadel of bad governance, match-fixing, and corruption. Back in 2000, the work of match-fixers in Zimbabwe can already be discerned when a seemingly fake El Salvador national team came and played the Zimbabwean team. The El Salvador

\footnotetext{
* Correspondence address: Faculty of Social Studies, University of Zimbabwe, P.O. Box MP 167, Mount Pleasant, Harare, Zimbabwe, e-mail: manasekudzai@gmail.com.
} 
football association had no knowledge of the team and the issue did not raise too much discussion in Zimbabwe. It is not clear then how long match-fixing has thrived in Zimbabwe without the notice of the authorities (Players exposed to match fixers, 2012). The post- 2000 crises characterized by widespread poverty, suffering, and shrinking earnings have also negatively affected footballers leading to a report by FIFPRO concluding that the poor salaries, lack of payments and general lack amongst players in the Zimbabwean league make the players susceptible to match-fixing approaches (Foster, 2017). This context in many ways explains the events surrounding Asiagate where poorly remunerated players became pawns for greedy and powerful political players.

\section{The global context of football corruption and match-fixing}

The involvement of organized crime in match-fixing poses serious challenges not only for football authorities, but also for national governments. The lucrative nature of matchfixing makes it an important space for criminal activities. For example, Qatar-based International Centre for Sports Security (ICSS) notes that criminals laundered $\$ 140$ billion a year through crooked sports betting (Match fixing in football: How high does it go?, 2014). The major criminal organizations involved in match-fixing are based in Europe and Asia as Chris Eaton noted in an interview An Italian investigation into matchfixing in that country:

[...] up to two billion Euros has been identified as being the likely criminal income to two major criminal organizations, the Camorra and the Mafia. And remember, this is a digital money. So there is no border transfer and no risk associated with importation, product problems or massive amounts of people you have to corrupt. Organized criminals are thus at the heart of fuelling match-fixing because of the rich rewards and relatively low risk associated with the activity. In Africa, one name has been synonymous with some of the major match-fixing scandals: Wilson Raj Perumal, a convicted match-fixer and Singaporean national. In his book the 'Kelok Kings' accuses his fellow Singaporean, Dan Tan, of being its kingpin. He claimed to have rigged outcomes of a 2010 Egypt-Australia friendly, which Egypt won 3-0 through arranging with Bulgarian referee to officiate the match and had his gambling syndicate make bets that there would be a total of three goals scored in the match (Soccer match fixing scandal deepens, 2014).

The organized nature of match-fixing syndicates provides difficulties for the authorities in Africa which have limited resources to track and combat international rings. The criminal rings involve local actors who facilitate access and ensure transactions. For example, "The Guardian" newspaper in Nigeria noted how a registered FIFA agent was working with a senior football administrator in Ghana to fix matches before the 2014 World Cup. What is clear, however, is the emergence of international and global networks of match-fixers who are increasingly becoming sophisticated. "The Guardian" in Nigeria reports: 
With the illegal betting market in Asia worth hundreds of millions of pounds, the tentacles of organized crime have reached into football leagues from Australia to Finland. Gambling on soccer, legal and illegal, amounts to $\$ 320$ billion yearly, the World Lottery Association estimates. Majority of the revenues are generated in Asia, where gambling is unregulated. At the top of the organization are men from Singapore, who are those who move the money, but the shareholders are divided from the West to the Far East, to South America and they manage with their men how to change the outcome of football matches. The match-fixing ring stretches from mafia influence in Naples to Singapore, and from bookmakers to criminal enterprises in South America and Hungary. Scandals involving rigged matches have sprouted like mushrooms in Turkey, Finland, South Korea, Germany, El Salvador, Israel, China, Thailand, Zimbabwe and beyond (Okpara, Nwakunor, Monye, 2015).

The global nature of the syndicates has made it impossible to develop countermeasures that guide against such practices. The predatory nature of these syndicates provides another layer of complexity in that they use and dump vulnerable actors, such as players, with little monetary gain that cannot sustain them if ever they are banned from playing football.

The rise of information technology has led to increased ease in match-fixing. The rise of online betting companies has made football accessible across the world. African countries are witnessing the rise of betting halls where football from little known leagues from across the world is used for betting purposes. Most countries in Africa and across the world have been slow to regulate the Internet, leading to unregulated movement of money and a globalized betting network. Francesco Barranca, the general secretary of Federbet, argued that:

In the past, without technologies, it was not so easy to bet on a match of second division in Czech Republic and of course the offer of the bookmaker was very reduced. Now if someone wants to bet 500,000 Euros on match of Premier League, he just has to put the money with this Asian bookmaker and very easily without any kind of check (Killing the ball, 2015).

Asia has emerged as an important market for match-fixing with the exponential growth of illegal gambling syndicates and the millions of dollars involved in these activities. Whilst it is difficult to understand the true value of illegal betting, the Gross Gaming Revenue (GGR) estimated that the regulated sports betting reached $\$ 70$ billion in 2016. Most of these activities emanate in Asia. Herman Van Rompuy notes that the professional match-fixers mainly utilize illegal Asian betting markets because

$[\ldots]$ bets are collected from the street, in betting shops, online and through telephone betting and are passed up through a hierarchical agent system - allows bets to be placed anonymously and without betting limits. To manage their risks, local illegal operators lay off their unbalanced bets along the chain to the next tier. Eventually, many of the bets end up with the largest Asian bookmakers licensed in loosely regulated jurisdictions, such as the Philippines. By then the bets are hidden in larger parcels and almost impossible to trace back to their source (Van Rompuy, 2016: 237). 
In understanding the political factors that fuel match-fixing in Africa, there is a need to analyze the lack of structures in most countries to effectively deal with this problem. Most nations have neither the resources nor expertise to respond to sophisticated global match-fixing syndicates. The lack of political will to fight many other forms of corruption makes it difficult to combat match-fixing. The political system in most African countries makes the continent an excellent ground for organized match-fixers to operate as will be shown by the examples later in this paper. Manase Kudzai Chiweshe provides context by outlining that "African football, as with its politics, has developed a system of patronage in which rich and powerful individuals use their positions within football to amass wealth, power and continued political influence. This is what Price terms the 'Big Man Small Boy Syndrome' in which The Big Man controls and gives orders; the Small Boy obeys and does not dare to speak his mind" (Chiweshe, 2014: 23).

\section{Zimbabwe's Asiagate}

The Zimbabwean national team took part in tours to Asia where then "captain Method Mwanjali and other players gave sworn statements admitting taking between $\$ 500$ and $\$ 1,500$ to lose matches by specific scores on a 2009 tour to Thailand and Malaysia" (Tanner, Dunbar, 2011). In the context of this chapter, it is important to note how this scandal is intricately linked with local football structures in Zimbabwe. Whilst the match-fixing was international in nature, it had two key localizing agents: firstly, the involvement of local players, journalists, coaches, and officials. In many ways, the suspensions that followed Asiagate only affected local players, such as Guthrie Zhokinyi, and not players based outside Zimbabwe. Secondly, during that period club side Monomotapa Football Club impersonated twice the national team playing games in Malaysia and lost 4 nil in one of the games. The now-defunct local club masqueraded as the Zimbabwe national football team during these trips. This shows that whilst Asiagate was an international scandal, it was grounded within the context of local football in Zimbabwe.

The role of Monomotapa in the match-fixing scandal goes beyond the Asian trips as noted by the testimony of Muthulisi Maphosa to the committee investigating Asiagate. Maphosa alleged that in 2009 some of his teammates and coach were paid money to fix the African champions league match against Etoile du Sahel in Tunisia. He narrated:

We conceded our first goal around 15 minutes from the start. Our goalkeeper slipped and fell on the ground when the ball went high. Even a small boy could have avoided that goal. To my surprise, the goalkeeper, who I knew that every time he concedes a goal gets angry, was in that instance smiling. When they were preparing the chairs, Dhlakama (the head coach) answered a call in English. After that call, he said to me that Sisi called and she was telling him that we were supposed to lose 3-0, so we had lost some money. I then asked who Sisi was, and he said Henrietta Rushwaya. That is when the guys sat on the bench said definitely something was happening because Clayton Munemo [team manager] never sat on the bench as, every three minutes or so, he was on the phone speaking in English. They even said they suspect that it must be the guys 
from Malaysia they saw when they played as the national team. Taurai Mangwiro (one of the coaches) said he was not part of it as he was surprised to hear Dhlakama telling Vorster (one of the defenders) that they should concede another goal. I then told Clayton how our keeper conceded the first goal. Clayton ended up accusing me of inciting the other guys to revolt. I headbutted him and he stormed out of my room (Asiagate scandal rocks Zimbabwe, 2012).

Again the role of Henrietta Rushwaya, the former chief executive officer of the Zimbabwe Football Association (ZIFA) is central to the Asiagate scheme as will be analyzed later in this section. The impact of the scandal has largely been felt by a struggling local league which has failed to attract meaningful corporate sponsorship and has clubs increasingly failing to meet the costs of managing the teams. It is important here to note that the Asiagate trips involved a myriad of actors including players, administrators, journalists politicians and also referees. The Ebrahim Commission, however, found no evidence implicating the participating referees in the match-fixing scandals (Asiagate woes for Marange, 2012).

At one time, 80 players were implicated and suspended by the national football body ZIFA (Smith, 2012). Later, the ZIFA chief executive officer at that time Henrietta Rushwaya was arrested by the Anti-Corruption Commission on charges related to Asiagate (Zimbabwe match fixing scandal turns deadly, 2012). ZIFA also instituted a probe led by Justice Ahmed Ebrahim which produced a 196-page report in which Rushwaya's role is narrated as:

'She [Rushwaya] wielded so much power in the association to become untouchable and a mini-god and could manipulate players and coaches alike to do her will' the report stated. 'Players were afraid of her and (ZIFA) board members also felt intimidated by her. The sheer number of players involved (in match-fixing) is forbidding' (Denials greet Asiagate report, 2012).

The ZIFA chairman and other officials are implicated in the report with many witnesses noting how Zimbabwean football officials, journalists, and football agents were all part of this criminal enterprise. For example, in his testimony Enerst Sibanda, who was the manager of the team that went to Malaysia for the Merdeka Cup in August 2007, noted the following:

During our first match, we were paid our money at halftime when we were actually losing 0 -2. We were told to concede another two goals in the second half. We were, by then, $\$ 1,000$ each richer. After the game, we were paid $\$ 1,000$ each, to the players, and $\$ 1,400$ to the technical team each. This was irresistible due to the financial meltdown in Zimbabwe by then. Mr. Wellington Nyatanga, the then ZIFA President, came to visit us just for the opening game and pocketing $\$ 10,000$, or so I was made to understand. He spent only one night and his room was then taken by head coach Sunday Chidzambwa. We also had, as part of our delegation, Mr Robson Sharuko and Josh Munthali. They were both accorded the officials (Zim) delegates status and we were all in it in all we did (Asiagate: Ernest Sibanda's evidence, 2011).

This was a well-coordinated and entrenched system of corruption in which even the media which at times plays a watchdog role over football officials are implicated. 
The players, whilst they were at the centre of throwing matches, were in many instances betrayed by the very officials which were supposed to betray them. ZIFA under a new president Cuthbert Dube and through the Justice Ebrahim commission ultimately decided the following:

[...] former Zifa chief executive officer Henrietta Rushwaya, former programmes officer Jonathan Musavengana, former Warriors coach Sunday Chidzambwa and ex-Monomotapa coach Rodwell Dhlakama received life bans. Former Premier Soccer League fixtures secretary Godfrey Japajapa, goalkeepers coach Emmanuel Nyahuma, match agent Kudzi Shaba, fitness trainer Thompson Matenda and journalists Robson Sharuko and Hope Chizuzu were also proscribed for life as well as five players. The banned players are former Warriors captain Method Mwanjali, axed Caps United goalkeeper Edmore Sibanda, Bidvest Wits defender Thomas Sweswe, former Njube Sundowns defender Danisa Phiri and Dynamos defender Guthrie Zhokinyi (Asiagate: 15 get life bans, 2012).

The journalists on this list never lost their jobs and by 2017 Sunday Chidzambwa was winning the COSAFA Castle Cup with the Zimbabwean national team. We, however, need to understand Asiagate within the context of the Zimbabwean context, especially between 2006 and 2010. This period was the peak of the post-2000 socio-economic crises which gripped the small southern African nation characterized by widespread poverty, food and cash shortages, political violence, hunger, unemployment and world record levels of inflation which led to the suspension and demonetizing of the national currency. In such a context of poverty, especially for football players who in some teams went for months without being paid, the lure of the American dollar and foreign trips where they would come back from with food and goodies was too much of a temptation to refuse (Asiagate to haunt Zimbabwe, 2012).

The role of journalists in the whole sordid affair was probably the most worrying. This is because the media is an important institution in entrenching and promoting accountability and transparency in public institution. Multiple questionable trips to Asia were only possible because of the acquiescence of journalists who were supposed to investigate and inform the nation of the corrupt activities. Lyton Ncube, in an insightful analysis of the role played by journalists in Asiagate, utilizes the concept of "brown envelope journalism" to conclude: "some journalists were 'seduced' by 'brown envelopes' and 'recruited' into a 'patronage' corrupt network by match-fixers. Consequently, 'patronised' journalists became pliant tools in hands of match fixers and failed to 'bark' at the malpractices masterminded by their 'benefactors"' (Ncube, 2017). Testimonies to the commissions investigating Asiagate allege the involvement of journalists and their role cannot be overestimated in sanitising, hiding the corruption and match-fixing in plain sight. The media as a key stakeholder in improving football in Zimbabwe become intricately intertwined in a diabolical scheme which regressed the development of the game in the country.

Asiagate also involved key political actors who in many ways remained behind the scenes and the full scope of their involvement is still unknown. There are, however, spe- 
cific examples of stories that have emerged to show how politicians were part of the intricate web of actors involved in the scandal. In any case, some of the key known actors, such as Rushwaya, have multiple political connections and usually run also for a political office. One of the state witnesses, former ZIFA board member Mwandimbuya Mutepfa, giving evidence in the trial of Rushwaya for match-fixing in 2012 noted that one of the Asiagate trips by the football national team was arranged by then ZANU PF minister Walter Muzembi who also imposed as a head of the delegation (Mzembi fingered in Asiagate trial, 2012). It is not, however, clear what other actions beyond that the former minister was involved in. The investigation into Asiagate more than anything else showed that there is no paper trail at ZIFA about the trips (ZIFA's Asiagate probe commendable, 2011). In any case, when called up to testify at another trial, Muzembi was saved by the Attorney General's office which told him not to appear in court (Why the sudden interest in Asiagate, 2013).

More than anything else Asiagate showed the many gaps in the administration of football in Zimbabwe. It highlighted the problems that emanate from having national associations that are not accountable to any local institutions, but only to FIFA (Chiweshe, 2014). National sports associations are technically under the supervision of a government body called the Sports and Recreation Council (SRC). The council is a legal body through an act of parliament, thus, it is important to analyze its role in the Asiagate scandal. Section 28 of the SRC Act shows that national associations are required to seek clearance from the council when undertaking any travel to foreign countries. In the case of Asiagate, Rushwaya is alleged to have circumvented this step by not informing the SRC and ensuring the visas were prepared a day before the departure of players (Asiagate to haunt Zimbabwe, 2012). ZIFA, thus, operated outside the legal framework of Zimbabwe knowing that the government was powerless to enforce its own laws because of FIFA's non-interference rule (Chiweshe, 2014). One of the coaches on the trips to Malaysia alleged that:

All the Asia games were undertaken to make money for individual officials and players and not ZIFA. You did not need a coach to go with the team as evidenced by the manner the squad was selected and assembled. Motivating the players to lose was very easy, as the take home stakes for losing, were high. To win a match, ZIFA would pay a player $\$ 100$ and, to lose, the syndicate would pay a player $\$ 4000$, etc. Everyone who went as a player and part of the management, i.e. officials, in any of these games, knew very well what was happening. No one can truthfully say they didn't know, especially, the technical team and senior players (ZIFA Asiagate report: The submissions 2, 2011).

The testimony highlights how Asiagate became an institutionalized and systematic operation including all the sectors of the Zimbabwean football family. The actions were brazen and in many ways reflect the context of the times. Numerous studies have shown that corruption is a part of everyday life in Zimbabwe (Chiweshe, 2015; Yamamoto, 2014; Final Report: Zimbabwe (2006/7), 2007; ACT Southern Africa, 2012). Given 
the widespread poverty the footballers were suffering from, the lure of the US dollar was too good to overcome.

The official Zimbabwean government understanding of Asiagate as contained in the First Report of the Portfolio Committee on Education, Sport, Arts and Culture on the Administration of Soccer in Zimbabwe and Issues Surrounding the Asiagate Scandal states as follows:

4.6.1 The Asiagate scandal was highlighted as the biggest scandal to have hit local football and has brought to the fore a great deal of challenges for local football.

4.6.2 The scandal took place between 2007 and 2010 when the National Team played most of the matches against light weighed national teams from Asia. The Asian betting syndicates influenced the outcome of the matches by offering huge sums of money for Zimbabwe National Team to lose games.

4.6.3 A record of 88 players took part in the 'fixed' games in the Far East and East Africa.

4.6.4 The Asian betting syndicate was working in cahoots with locals namely the former CEO Ms. Henrietta Rushwaya, Kudzi Shaba, Jonathan Musavengana and Mr. Tafirenyika Chitsungo.

4.6.5 The impact of the scandal is set to be felt for the next five years through poor performance, indiscipline, lack of patriotism and mercenary conduct.

4.6.6 ZIFA set up an Investigating Committee headed by Mr. Ndumiso Gumede (ZIFA Vice President) and the Committee produced a 162-page report on the scandal. The report was sent to SRC, COSAFA, CAF and FIFA.

4.6.7 To date, ZIFA has suspended all individuals from all national teams fingered in the report. ZIFA referred some of the cases to the Zimbabwe Republic Police and the Anti-Corruption Commission (Portfolio Committee on Education, Sport, Arts and Culture, 2013:8).

Yet by 2019, the named individuals in this report were still walking free with Rushwaya actually leading another institution despite the history of maleficence. The politics of Asiagate serves as a reminder of how politically connected architects of scandalous networks often remain unscathed.

In 2016, there was another match-fixing scandal coined Limpopogate in which it was alleged that a match-fixing syndicate had targeted Zimbabwe versus Swaziland 2017 African Nations Cup qualifier. It was alleged that ZIFA committee member, the late Edzai Kasinauyo was behind this scheme and he was suspended from football-related activities. The suspension together with that of Ian Gorowa and Nation Dube was later lifted mainly because the courts had dismissed the evidence led by the association's whistle-blower (ZIFA lift Limpopogate sanctions, 2017). Whilst this case was shrouded with many irregularities, it is clear that the scourge of match-fixing still haunts Zimbabwean football. The administrators and fans can no longer accept bad results without suspecting of some kind of foul play. The whole episode has diminished the growth of the game, especially the continued lack of corporate partners for many local teams struggling to function as economic entities. The fact that many of those implicated in the Asiagate scandal continued with their footballing careers even in the face of long term bans shows the lack of seriousness in tackling the issue. This is especially true in cases 
where South African football authorities did not implement the bans passed on many players playing in their league. This lack of unity of purpose among national football associations also points to a problematic context when dealing with match-fixing. What is clear, however, is that this scandal has also damaged the reputation of the local league and its ability to attract corporate partners.

\section{Conclusions}

The paper has provided a brief expose on the dynamics around one of Zimbabwean football's darkest chapter. It is shown how a network of criminality with global linkages and connected to local power brokers shaped match-fixing activities by Zimbabwean teams in Asia. After two investigations and reports, the masterminds behind the corrupt scheme in the top echelons of the Zimbabwe Football Association remain unaffected by the fallout from the scandal. The paper has argued that for the players involved, it is important to analyze their actions and decision making within a context of a deepening economic crisis which had eroded their earnings and affected the frequency of getting paid. Asiagate, thus, appeared as an opportunity to make easy money and became an enviable opportunity for many. Through the use of excerpts from the reports, the paper has shown how even important institutions such as the media became accomplices to the corrupt scheme. The paper concludes by noting that the whilst conditions of poverty and lack continue amongst players in Zimbabwe and there are no mechanisms to guide against match-fixing, events of Asiagate will continue in various forms. The emergence of betting on local teams is one such important development where unscrupulous players can bet and shape results in return for winnings. Another important issue is that the lack of punishment for local power brokers in Asiagate erodes any confidence people have in the institutions that should protect the integrity of football. It places a dangerous precedent that powerful enough individuals can get away with shaming the nation in such an embarrassing manner.

\section{Bibliography}

ACT Southern Africa (2012), Zimbabwe: Corruption Cases: Lest We Forget: Bad Leadership Examples for Accountability, Transparency and Integrity in Zimbabwe, Harare.

Asiagate scandal rocks Zimbabwe (2012), http://www.sportdw.com/2012/03/asiagate-scandalrocks-zimbabwean.html [access on: 10.01.2019].

Asiagate to haunt Zimbabwe (2012), https://www.herald.co.zw/asiagate-to-haunt-zim-mahere/ [access on: 10.08.2018].

Asiagate woes for Marange (2012), https://www.newsday.co.zw/2012/11/asiagate-woes-formarange/ [access on: 17.09.2018].

Asiagate: 15 get life bans (2012), https://www.newsday.co.zw/2012/10/20/asiagate-15-get-life-bans/ [access on: 13.08.2018].

Asiagate: Ernest Sibanda's evidence (2011), http://www.newzimbabwe.com/sports-5565-Asiagate\%20Ernest\%20Sibandas\%20evidence/sports.aspx [access on: 3.11.2018]. 
Asiagate: ZIFA vindicated (2014), https://www.southerneye.co.zw/2014/08/29/asiagate-zifavindicated/ [access on: 13.08.2018].

Chiweshe M.K (2014), The Problem with African Football: Corruption and the (Under)Development of the Game on the Continent, "African Sports Law and Business Bulletin", No. 2, pp. 27-33.

Chiweshe M.K. (2015), Foucault, power and abuse of authority: Towards a sociology of corruption in Zimbabwe, https://www.tni.org/files/download/power_and_corruption_paper.pdf [access on: 11.06.2019].

Denials greet Asiagate report (2012), http://www.newzimbabwe.com/sports-5586-Denials\%20 greet\%20Asiagate\%20report/sports.aspx [access on: 13.02.2019].

Final Report: Zimbabwe (2006/7) (2007), http://www.transparency.org/policy_research/nis/ nis_reports_by_country [access on: 23.11.2018].

Foster R. (2017), Footballers living on the breadline: low wages, short contracts and no security, "The Guardian", 24.08.2017, https://www.theguardian.com/football/the-agony-and-the-ecstasy/2017/aug/24/footballers-breadline-low-wages-no-security-little-glamour [access on: 23.11.2018].

Killing the ball (2015), http://www.aljazeera.com/programmes/peopleandpower/2015/02/killingball-150218120522829.html [access on: 13.08.2018].

Match fixing in football: How high does it go? (2014), http://www.economist.com/news/ international/21606883-not-even-games-grandest-tournament-free-allegations-rigging-howhigh-does-it [access on: 3.12.2018].

Mzembi fingered in Asiagate trial (2012), https://www.newsday.co.zw/2012/11/mzembi-fingeredin-asiagate-trial/ [access on: 9.12.2018].

Ncube L. (2017), Sport's journalists and corruption in Zimbabwean football: Reflections on the Asia-gate scandal, "Communicatio", Vol. 43, No. 3-4, pp. 19-35.

Okpara C., Nwakunor G.A., Monye A. (2015), Reality of match fixing and why Africa may never win world cup, "The Guardian”, 1.09.2015, https://guardian.ng/news/reality-of-match-fixingand-why-africa-may-never-win-world-cup/ [access on: 15.03.2019].

Players exposed to match fixers (2012), https://www.thestandard.co.zw/2012/10/28/playersexposed-to-match-fixers/ [access on: 11.01.19].

Portfolio Committee on Education, Sport, Arts and Culture (2013), First Report of the Portfolio Committee on Education, Sport, Arts and Culture on the Administration of Soccer in Zimbabwe and Issues Surrounding the Asiagate Scandal, http://www.veritaszim.net/sites/veritas_d/files/ SC\%202013-01\%20-\%20Portfolio\%20Committee\%20Report\%20-\%20Soccer\%20Administration\%20\%26\%20Asiagate\%20Match-Fixing\%20Scandal.doc [access on: 12.02.2019].

Smith D. (2012), Zimbabwe footballers suspended, “The Guardian”, 1.02.2012, https://www.theguardian.com/world/2012/feb/01/zimbabwe-footballers-suspended-asiagate-match-fixing [access on: 13.08.2018].

Soccer match fixing scandal deepens (2014), http://www.theaustralian.com.au/sport/football/ soccer-matchfixing-scandal-deepens/story-fn63e0vj-1226938803516?nk=2aac7c687b14bf5 7462b908f6109f7d8 [access on: 12.02.2019].

Tanner J., Dunbar G. (2011), Singaporean convicted of match fixing in Finland, “The San Diego Union-Tribune", 19.07.2011, http://www.sandiegouniontribune.com/sdut-singaporeanconvicted-of-match-fixing-in-finland-2011jul19-story.html [access on: 17.08.2018].

Van Rompuy B. (2016), The role of the betting industry, "Transparency International Global Corruption Report: Sport", New York.

Why the sudden interest in Asiagate (2013), https://www.newsday.co.zw/2013/01/why-the-suddeninterest-in-asiagate/ [access on: 11.09.2018]. 
Yamamoto K. (2014), Mugabe fighting corruption? Forget it!, "New Zimbabwe News”, http://www. newzimbabwe.com/news15219Mugabe+fighting+corruption+Forget+it!/news.aspx [access on: 12.08.2018].

ZIFA Asiagate report: The submissions 2 (2011), https://www.chronicle.co.zw/zifa-asiagate-reportthe-submissions-2/ [access on: 3.02.2019].

ZIFA lift Limpopogate sanctions (2017), http://www.herald.co.zw/zifa-lift-limpopogate-sanctions/ [access on: 15.08.2018].

ZIFA's Asiagate probe commendable (2011), https://www.newsday.co.zw/2011/10/2011-10-28-comment-zifas-asiagate-probe-commendable/ [access on: 15.08.2018].

Zimbabwe match fixing scandal turns deadly (2012), http://www.theafricareport.com/Societyand-Culture/zimbabwe-match-fixing-scandal-turns-deadly.html [access on: 05.12.2018].

Abstract: Football is the most popular game in Zimbabwe. Events and activities in this sport in many ways mirror the state of wider society in the country. This paper provides a grounded critique of how money, football and politics intersect through the lens of the Asiagate match-fixing scandal which engulfed post-2000 Zimbabwe. It utilizes reports and transcripts from the investigation to highlight the role of various actors in the match-fixing scandal including administrators, politicians, coaches, players, referees, and journalists. The paper argues that Asiagate needs to be understood in the context of the globalization of match-fixing and the socio-economic crises engulfing post-2000 Zimbabwe. The socio-economic crises characterized by widespread poverty and suffering left players vulnerable to match-fixers. The paper concludes that the politically connected and powerful players in the scandal were not held accountable and this has created precedence for the continued existence of match-fixing in Zimbabwean football.

Keywords: match-fixing, Asiagate, football, Zimbabwe

Article submitted: 11.06.2019; article accepted: 10.10.2019. 